\title{
Long-Term Coral Community Stability in a Disturbed Marginal Reef in Kuwait
}

\author{
Shaker Hamza Alhazeem ${ }^{1, ~ *, ~ J o h n ~ A . ~ B u r t ~}{ }^{2}$, Adel Hasan Alsaffar ${ }^{1}$, Weizhong Chen ${ }^{1}$, \\ Mohammad Abdulla Al-Kandari ${ }^{1}$ \\ ${ }^{1}$ Ecosystem-Based Management of Marine Resources Program, Environment and Life Sciences Research Centre, Kuwait Institute for \\ Scientific Research, AlSalmyah, Kuwait \\ ${ }^{2}$ Center for Genomics and Systems Biology, New York University Abu Dhabi, Abu Dhabi, UAE
}

\section{Email address:}

salhazeem@gmail.com (S. H. Alhazeem), shazeem@kisr.edu.kw (S. H. Alhazeem)

${ }^{*}$ Corresponding author

\section{To cite this article:}

Shaker Hamza Alhazeem, John A. Burt, Adel Hasan Alsaffar, Weizhong Chen, Mohammad Abdulla Al-Kandari. Long-Term Coral Community Stability in a Disturbed Marginal Reef in Kuwait. Journal of Water Resources and Ocean Science.

Vol. 6, No. 6, 2017, pp. 85-89. doi: 10.11648/j.wros.20170606.12

Received: August 22, 2017; Accepted: October 16, 2017; Published: November 29, 2017

\begin{abstract}
Coral reefs in Kuwait occur at high latitude $(29 \mathrm{~N})$ and in in extreme environmental conditions (SST range: $13^{\circ} \mathrm{C}$ to $32^{\circ} \mathrm{C}$, annually), and have been subject to chronic anthropogenic pressure in recent decades (recurrent bleaching, oil spills, chronic recreational anchoring and diving impacts). We surveyed coral communities at six sites around Kubbar Island in 2015 and compared these to quantitative survey results collected at the same sites 31 years earlier (1984) as well as to results from several sites resurveyed a decade ago (2003) in order to characterize changes in coral community structure in this marginal reef environment. Mean coral cover was $25 \%$ in 2015 compared with 34\% in 1984, but declines in coral cover were significant at only one site. The decline in coral cover at this single site was mainly due to a $>80 \%$ loss of formerly dominant Acropora, and a concomitant shift towards a lower cover community dominated by massive corals. A total of 13 coral genera were observed across sites, comparable to the 12 observed in 1984 and the 13 observed in 2003 . Overall, the results of this study indicate a high degree of long term stability in coral community structure in the marginal and heavily disturbed environment of northern Kuwait.
\end{abstract}

Keywords: Coral, Community, Kuwait, Resilience, Stability

\section{Introduction}

Coral communities in Kuwait occur in one of the most environmentally extreme coral habitats in the world. These high-latitude communities occur at the far northern reaches of the Persian Gulf, representing the most northern distribution of corals in the wider Indian Ocean. Due to its shallow depth, the arid nature of the surrounding environment, and the limited input of freshwater, the waters of the northern Persian Gulf are characterized by high salinity and temperatures ranging from $<13^{\circ} \mathrm{C}$ to $>30^{\circ} \mathrm{C}$ annually [1]. Despite these harsh conditions, coral reefs occur in both the nearshore and offshore environments of Kuwait, with the offshore coral cays representing some of the best developed true coral reefs in the Arabian Gulf $[2,3]$.
Kubbar Island is one of the most substantial coral cays in Kuwait, located approximately $50 \mathrm{~km}$ southwest of Kuwait City and occurring as the northernmost major reef complex in the Arabian Gulf [3]. Kubbar reef surrounds a sandy island of 1.3 by $0.5 \mathrm{~km}$, with reef framework extending several hundred meters from shore across shallow $(<2 \mathrm{~m})$ flats and peripheral slopes, with substantial coral occurring to a depth of ca. $18 \mathrm{~m}$ before grading to sand [1]. National surveys conducted in the early 1980s showed Kubbar to be among the most speciose and highest coral covered reefs in Kuwait [1, 4].

Despite being among the most important coral reef habitats in Kuwait, Kubbar reef has been under increasing pressure in the past several decades. Being the closest major coral cay to Kuwait city, Kubbar reef is heavily utilized by recreational divers, spearfishers, and boaters, with an estimated $>50$ boats 
anchoring directly on the reef flat during peak periods [1]. Resultant anchor damage has had chronic impacts to this reef since the 1980s, with fragile branching corals particularly affected. Cold-water bleaching resulted in substantial loss of Acropora from shallow reef habitats in the winter of 1982 and 1985 [6], and these effects were exacerbated by purported winter bleaching in 1991 [7, 8], as well as additional bleaching related to elevated summer temperatures during the summer of 1998. Periodic outbreaks of the boring urchin Echinometra matthai have accompanied previous bleaching events (mean densities 62 urchins $\mathrm{m}^{-2}$ and maximum densities $\left.>100 \mathrm{~m}^{-2} ; 7,5\right)$, and these have been suggested to be responsible for substantial bioerosion of reef framework in the years following stress [8]. These impacts are likely exacerbated by the naturally extreme environmental conditions experienced at Kubbar, where both extreme high $\left(31.5^{\circ} \mathrm{C}\right)$ and low $\left(13.2^{\circ} \mathrm{C}\right)$ temperatures have been recorded, and naturally high salinity (42.4 PSU) and turbidity (13.2 NTU) also occur [4].

The purpose of this study was to provide a current assessment of the condition and composition of the coral community at Kubbar reef. Being one of the most important reef sites in Kuwait, the reef at Kubbar has been extensively surveyed in the past, providing a baseline against which to compare the status of the current coral community. Downing (1989) performed detailed quantitative assessments of a series of sites along Kubbar's reef in 1986, providing descriptions of the coral community structure along with GPS coordinates of the individual sampling locations. These detailed quantitative descriptions were supplemented by more general qualitative reports by the same author in the 1980s [4, 9], and semi- quantitative and qualitative descriptions of the general reef area were also produced from surveys performed at Kubbar immediately before and/or after the 1991 Gulf $[3,5,10]$. Later work by Benzoni et al. (2006) provided further quantitative assessment of the coral community in 2002-3, with their efforts focused specifically on several sites that had been surveyed in the 1980s by Downing (1989). Together, these data provide a dataset spanning over three decades, providing an opportunity for an assessment of the current status of this reef and any changes in community structure that may have occurred over the long-term.

\section{Materials and Methods}

To assess the current status of Kubbar's reef, we selected five sites that had been sampled earlier for comparative surveys in 2015 (Figure 1). Each of these sites had been intensive sampled in 1986 by Downing (1989), and for which GPS coordinates, transect data, and quantitative data on the benthic community are available. These are represented as Sites $1-5$ in the present study, corresponding to Transects 14, and 6 from the 1986 surveys [1]. As indicated in Figure 1, the 2015 survey anchorage points closely correspond to the anchorage points reported for Downing (1986) from which his surveys commenced; in both cases, surveys were conducted laterally and inward from the anchorage point (see below). In addition, two of these sites were also surveyed by Benzoni et al. (2006) in 2002-3, with their survey sites ' $\mathrm{K} 1$ ' and 'K2' corresponding to Site 4 and Site 2 in this study and in Downing's (1989) survey.

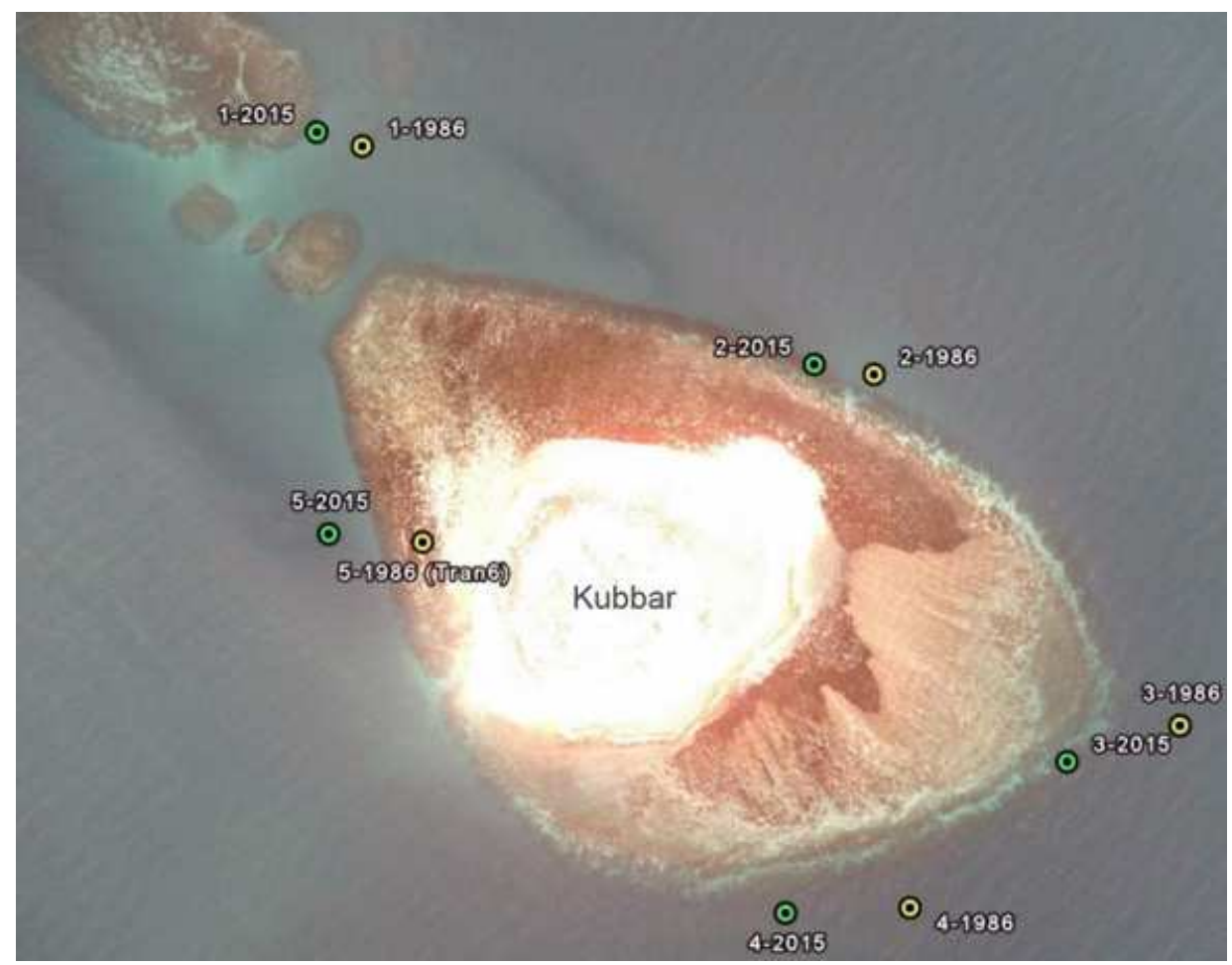

Figure 1. Anchoring locations for survey sites in the current study (2015, green) relative to the anchoring points for surveys performed in 1986 (yellow) by Downing (1989). 
Photo quadrats were used to survey the reef community at each of the five sampling sites. At each site six replicate 30 $\mathrm{m}$ transect tapes were laid out perpendicular to the reef slope ca. $5 \mathrm{~m}$ apart, with the deepest point starting ca. $10 \mathrm{~m}$ in from the reef base and transects extending up the reef slope, providing broad coverage of the same general reef areas that were surveyed by earlier authors. Depth at the base of the transects ranges from 4 to $8 \mathrm{~m}$, and was ca. $2 \mathrm{~m}$ depth at the shoreward end. A Nikon D700 dSLR camera mounted to a frame enclosing a $0.25 \mathrm{~m}^{2}$ quadrat area was used to capture high-resolution digital images of quadrats at $3 \mathrm{~m}$ interval along each transect, for a total of 11 quadrats per transect and 66 quadrats per site. This technique has been successfully used to characterize coral communities in several other nations bordering the Arabian Gulf $[11,12,13 ; 14]$.

Quality of digital quadrat photos was optimized in Adobe Photoshop by adjusting color and uploaded to Coral Net (www.coralnet.ucsd.edu) for subsequent image analyses. To estimate percent coverage and composition of the coral community, 50 points were assigned randomly across each quadrat image. Substrates underlying each point were classified into major benthic categories (e. g. turf algae, rock, sand, etc), with corals identified to genus. Data were pooled at the transect level and compared between sites. One-way Analyses of Variance (ANOVAs) were used to test for differences in mean coral cover and genera per transect between sites, and post-hoc Tukey's tests used to identify differences between individual sites. Coral cover was converted to proportions and arcsine-square transformed and the number of genera $\log _{(\mathrm{n}+1)}$ transformed prior to analyses. Differences in coral generic composition were compared graphically between sites. In order to compare data from this study with that of Downing (1989), a two-way ANOVA was used to compare coral cover among the main effects of sites (Sites 1-5) and years (1986 vs. 2015). To identify significantly different groups, a post-hoc unequal-N HSD test was used in order to account for Downing (1989) having 4-5 transects per site versus the six transects sampled here.

\section{Results and Discussion}

The fringing reef surrounding Kubbar island represents one of the best develop reef systems in the Arabian Gulf, and one of the most important coral communities in Kuwait. Since the area was first surveyed in the mid-1980s the coral reef at Kubbar has been suggested to be under pressure from a variety of stressor including recurrent bleaching events associated with extreme temperatures, potential impacts from reduced solar insolation during the first Gulf War, long-term damage from recreational boat anchoring and fishing activities, as well as other factors $[2,3,4,1,10,6]$.

Figure 2 compares coral cover from 1986 against coral cover observed in this current study, nearly three decades later. Although coral cover appears to vary between years at each site, analyses showed that this was significant in only one instance; a two-way ANOVA showed a significant interaction between the main effects of year and site (Year*Site $F_{(4,40)}=6.8, p<0.001$ ). In terms of differences between sampling periods, the only site for which there has been a significant change in coral cover over time occurred at Site 2, where coral cover had declined by almost half between 1986 and 2015 (Unequal-N HSD $p<0.05$ ); at each other site there was no significant change in coral cover between 1986 and 2015 ( $p>0.05$ each). In terms of spatial differences between sites, in the current study coral cover was lowest at Site 1 (ca. 17\% cover), located at the shallow $(2-4 \mathrm{~m})$ reef patch located $500 \mathrm{~m}$ northwest of the main island reef; Site 1 had significantly lower coral than Site 4 and $5(\mathrm{p}<0.05)$ but was comparable $(\mathrm{p}>0.05)$ to the moderate coral cover at Sites 2 and 3 on eastern Kubbar (Figure 2). Coral cover was highest at the southern Site 4, where live coral covered $38 \%$ of the substrate and this was significantly higher than at Sites 1-3 ( $<<0.05$ each). Site 5 on western Kubbar contained an intermediate amount of coral that was statistically comparable to all sites except Site 1 in the current study. In 1986 there were no significant differences among sites ( $p>0.05$ for each comparison).

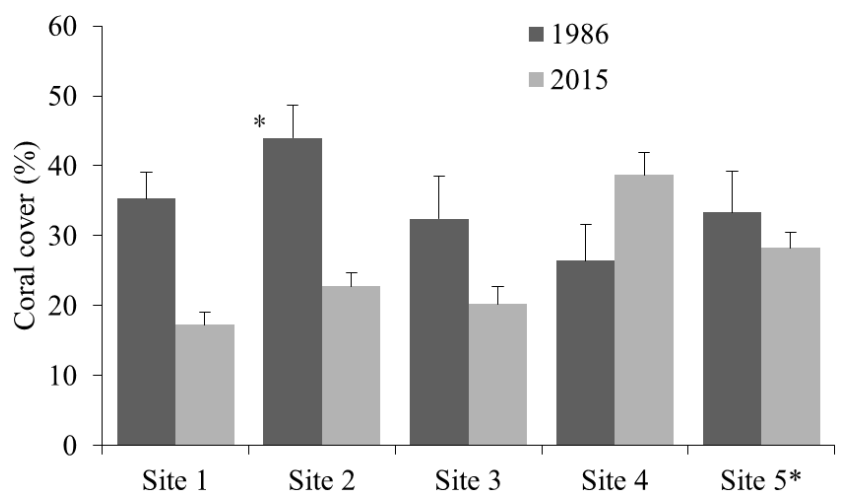

Figure 2. Mean $( \pm S E)$ coral cover at the five sampling site from 2015 versus 1986 (from Downing, 1989). An asterisk indicates a significant difference between years at a site (Tukey's Unequal-N HSD test $p<0.05$ ).

Coral cover averaged $25 \%$ of substrate in 2015. Although slightly lower than the $34 \%$ coral cover observed across these same sites in 1986 [1], our analyses showed that coral cover only declined significantly at Site 2 over the intervening years and was comparable between periods at each other site. Surveys of Site 2 in 2002/3 by Benzoni et al. (2006) observed coral cover (44 - 49\%) similar to the $44 \%$ coral cover seen two decades earlier by Downing (1989). The coral community at Site 2 has consistently been dominated by Porites, with Favia (now Dipsastrea) and Cyphastrea also being common, similar to the community composition observed in this study (see below). Porites and small massive corals also dominated the Site 2 community in 2002/3 [2]. However, there has been substantial change in Acropora abundance which may have contributed to the significant decline in coral abundance at this site. Acropora table corals had made up an average of $5 \%$ of substrate (11\% of coral) across transects at Site 2 in 1986 [2], but were virtually nonexistent in the current study $(0.1 \%$ of substrate, $0.5 \%$ of 
coral). Acropora have always been relatively uncommon at Kubbar, with Downing (1989) reporting Acropora covering only $2.8 \%$ of substrate across transects at the sites examined in this study. Our results show that even this limited amount of Acropora has declined, with Acropora cover now just $0.5 \%$ across sites, representing a decline of more than $80 \%$ of its previous abundance. Site 2 had the highest abundance of Acropora of all sites in the 1986 surveys at Kubbar [1] and its subsequent loss thus had a differential impact on overall coral cover at this site. The exact cause for decline in Acropora is unclear, but the presence of numerous overturned Acropora skeletons on the reef suggests that boat anchor damage is likely impacting the table coral community, and that management intervention to prevent boat anchorage is warranted. However, bleaching may have also played a role. Acropora corals have been reported to be differentially lost from the coral communities of Kuwait and other Arabian Gulf reefs as a result of bleaching in the past $[12,14,1,5$, 15], and bleaching events have occurred with increasing frequency in recent years elsewhere in the Gulf $(2007,2009$, 2010, and 2012) [16, 15]. It is therefore possible that unreported bleaching events may also have contributed to the loss of Acropora table corals at Kubbar. Establishment of an annual monitoring program to track the status of coral communities and identify causes of coral declines is clearly warranted.

A total of 13 coral genera were observed at Kubbar island, with between 9 and 12 genera observed at each site (Figure 3 a; a detailed breakdown of coral genera observed at each site is provided in Supplementary Table 1 and Supplementary

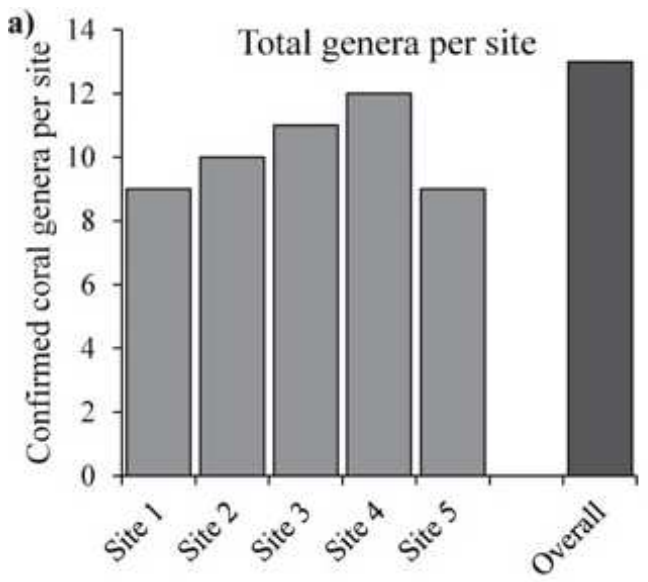

Figure 1). Similar to the patterns observed with coral cover, the highest generic diversity of corals was observed at Site 4, which had the highest number of genera of all sites (12 genera; Figure 3a), as well as significantly higher mean generic richness per transect (Figure $3 \mathrm{~b}$; ANOVA $F_{(4,25)}=3.7$, $\mathrm{p}<0.05$; post-hoc Tukey's test $\mathrm{p}<0.05$ ). Although a total of 26 coral genera have been reported for the entire nation [17], Benzoni et al. (2006) observed only 13 genera across the three major off-shore island reefs (Kubbar, Qaro, and Umm Al-Muradem), and Downing (1989) reported only 12 genera from transects conducted at Kubbar, suggesting that the 13 genera observed here are comparable to historical estimates of generic diversity. This study provides the first reported occurrence of two coral genera that had not been observed at Kubbar in past surveys: Acanthastrea and Anomastrea (represented here as A. maxima and $A$. irregularis, respectively). Each of these genera were known for other reefs in Kuwait, but had not been reported from earlier surveys at Kubbar by Downing (1989) or Benzoni et al. (2006), thus adding to the total diversity of corals known for this location. In terms of coral genera that had been observed in the past, Turbinaria were reported from Kubbar by Downing (1989) but were not observed in transects during this current study; they were, however, observed on the reef outside of transects and are thus still present at Kubbar. Leptastrea and Plesiastrea were observed by Downing (1989) but not by Benzoni et al. (2006), but were again observed in the current study, suggesting that these uncommon genera (together making up $<1 \%$ of substrates) were present but fell outside of transects during surveys by Benzoni et al (2006).

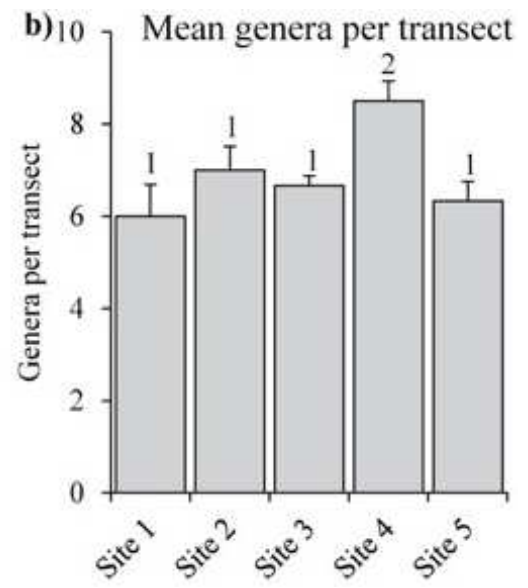

Figure 3. Number of hard coral genera observed at each site at Kubbar Island as (a) total observed overall at each site across all transects and (b) as mean genera per transect (where different numbers indicate significant differences between sites based on Tukey's tests, $p<0.05$ ).

\section{Conclusion}

Overall, the results of this study indicate that the coral community at Kubbar Island has remained relatively stable over the past three decades despite episodes of acute stressors (e.g. bleaching events and the Gulf War) and chronic pressure from recreational use and long-term environmental conditions. Coral cover has not changed significantly at most sites, and diversity of genera is comparable to historical observations. This being said, coral cover has declined significantly at one site (Site 2), and this appears to be largely due to substantial declines in Acropora table corals, which have also declined in general abundance across the island. Such changes may have implications for reef-associated fauna, and Kuwait is already considered to have among the highest number of threatened coral-dependent fishes in the Arabian Gulf [18]. Establishment of a long term monitoring program for this island and other offshore islands in Kuwait is needed to continuously survey the condition of these reefs 
and to determine the causes and potential management responses for changes in coral community structure.

\section{Appendix}

Table 1. Coral genera observed at each survey site at Kubbar Island.

\begin{tabular}{|c|c|c|c|c|c|}
\hline & Site 1 & Site 2 & Site 3 & Site 4 & Site 5 \\
\hline Acanthastrea & & & + & + & \\
\hline Acropora & + & + & & + & + \\
\hline Anomastrea & & + & + & & \\
\hline Coscinarea & + & + & + & + & + \\
\hline Cyphastrea & + & + & + & + & + \\
\hline Dipsastrea (former Favia) & + & + & + & + & + \\
\hline Favites & + & + & + & + & + \\
\hline Leptastrea & + & + & + & + & + \\
\hline Platygyra & + & + & + & + & + \\
\hline Plesiastrea & & & & + & \\
\hline Porites & + & + & + & + & + \\
\hline Psammocora & + & + & + & + & + \\
\hline Siderastrea & & & + & + & \\
\hline
\end{tabular}

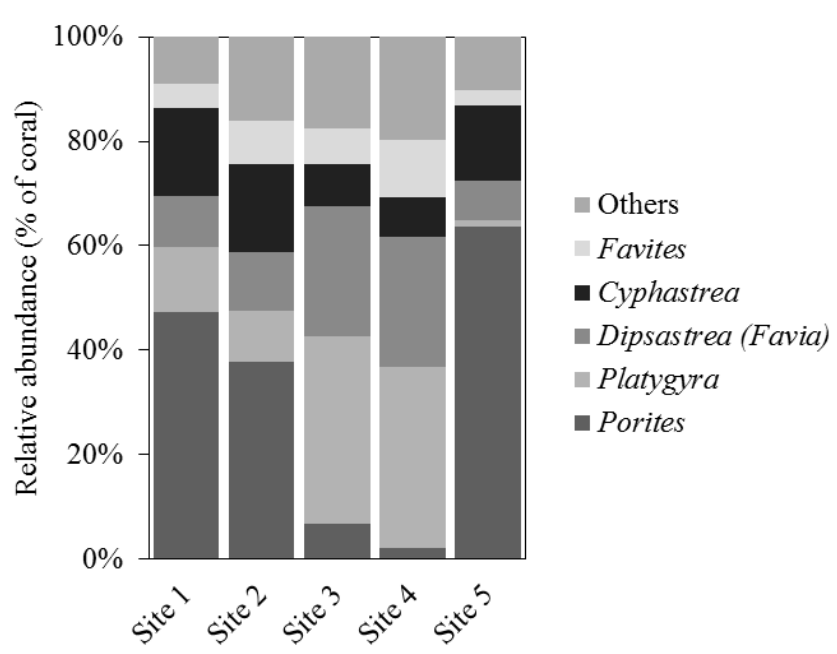

Figure 4. Relative abundance of the dominant genera making up the live coral community at Kubbar Island in 2015.

\section{References}

[1] Downing, N., 1989. Final report: A study of the corals and coral reef fishes of Kuwait, Volume II: the reef building corals Kuwait Institute for Scientific Research (Project MB-42), Kuwait.

[2] Benzoni, F., Pichon, M., Al-Hazeem, S., Gallo, P., 2006. The coral reefs of the northern Arabian Gulf: stability over time in extreme environmental conditions? Proceedings of the 10th International Coral Reef Symposium, Okinawa, Japan, 969975.

[3] Carpenter, K., Harrison, P., Hodgson, G., Alsaffar, A., Alhazeem, S., 1997. The corals and coral reef fishes of Kuwait. Kuwait Institute for Scientific Research, Kuwait.

[4] Downing, N., 1985. Coral reef communities in an extreme environment: the northwestern Arabian Gulf, Proceedings of the fifth International Coral Reef Congress (27 May -1 June, 1985), Tahiti, pp. 343-348.

[5] Downing, N., Roberts, C., 1993. Has the Gulf War affected coral reefs of the northwestern Gulf? Mar Pollut Bull 27, 149156.

[6] Gerges, M. A., 1993. On the impacts of the 1991 Gulf War on the environment of the region: General observations. Mar Pollut Bull 27, 305-314.

[7] Alsaffar, A. H., Lone, K. P., 2000. Reproductive cycles of Diadema setosum and Echinometra mathaei (Echinoidea: echinodermata) from Kuwait (northern Arabian Gulf). Bull Mar Sci 67, 845-856.

[8] Downing, N., El-Zahr, C. R., 1987. Gut evacuation and filling rates in the rock-boring sea urchin, Echinometra mathae. Bull Mar Sci 41, 579-584.

[9] Downing, N., 1988. The coral reefs and coral islands of Kuwait, Proceedings of the ROPME workshop on coastal area development. United Nations Environment Programme, UNEP Regional Seas Reports and Studies No. 90/ROPME Publication No. GC-5/006, pp. 73-78.

[10] Fadlallah, Y. H., Eakin, M., Allen, K., Rahim, R., ReakaKudla, M., Earle, S., 1993. Reef coral distribution and reproduction, community structure, and reef health (Qatar, Bahrain, Saudi Arabia, Kuwait): results of the RIV Mt. Mitchell Cruise, Proceedings of the Scientific Workshop on the Results of the Mt. Mitchell Cruise in the ROPME Sea Area, January 1993, Kuwait, pp. 1-26.

[11] Bento R, Hoey AS, Bauman AG, Feary DA, Burt JA (2016) The implications of recurrent disturbances within the world's hottest coral reef. Mar Pollut Bull 105:466-472.

[12] Burt, J., Al-Harthi, S., Al-Cibahy, A., 2011. Long-term impacts of bleaching events on the world's warmest reefs. Mar Environ Res 72, 225-229.

[13] Burt, J., Al-Khalifa, K., Khalaf, E., AlShuwaik, B., Abdulwahab, A., 2013. The continuing decline of coral reefs in Bahrain. Mar Pollut Bull 72, 357-363.

[14] Burt JA, Smith EG, Warren C, Dupont J (2016) An assessment of Qatar's coral communities in a regional context. Mar Pollut Bull 105:473-479.

[15] Riegl B, Purkis S (2015) Coral population dynamics across consecutive mass mortality events. Global Change Biology 21:3995-4005.

[16] Riegl, B., Purkis, S., 2012. Dynamics of Gulf coral communities: observations and models from the world's hottest coral sea, in: Riegl, B. M., Purkis, S. J. (Eds.), Coral reefs of the Gulf: adaptation to climatic extremes. Springer Science+Business Media B. V., pp. 71-93.

[17] Hodgson, G., Carpenter, K., 1995. Scleractinian corals of Kuwait. Pac Sci 49, 227-246.

[18] Buchanan JR, Krupp F, Burt JA, Feary DA, Ralph GM, Carpenter KE (2016) Living on the edge: Vulnerability of coral-dependent fishes in the Gulf. Mar Pollut Bull 105:480488 . 